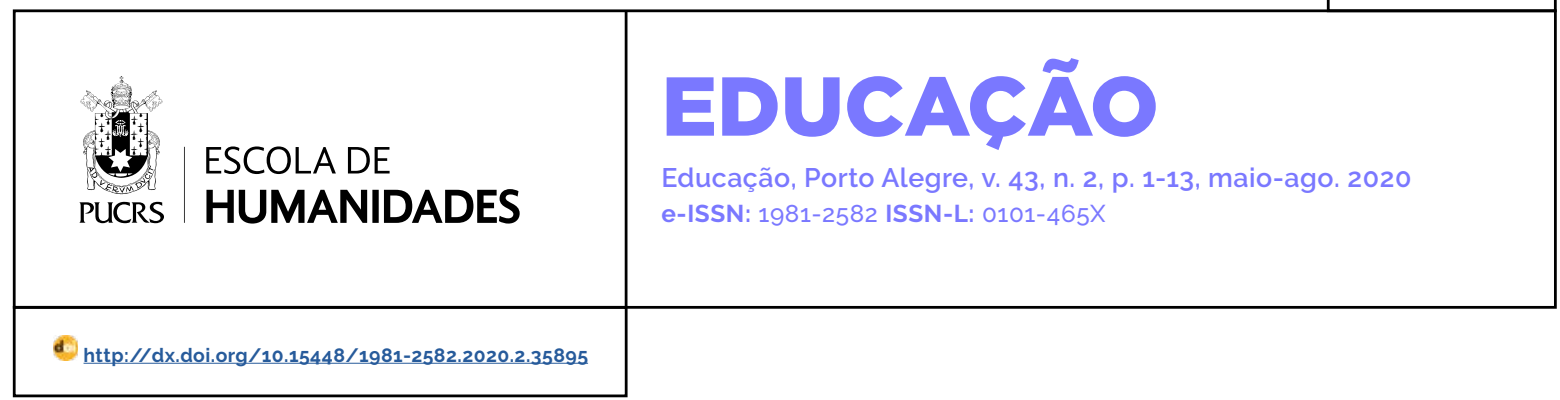

DOSSIÊ

\title{
Conservadorismo moral, indeterminação da condição humana e ética democrática
}

\author{
Moral conservatism, indeterminacy of the human condition and democratic ethics \\ Conservacionismo moral, indeterminación de la condición humana y ética democrática
}

Claudio Almir Dalbosco ${ }^{1}$ orcid.org/0000-0003-3408-2975 cadalbosco@upf.br

\section{Angelo Vitório Cenci ${ }^{1}$ orcid.org/0000-0003-0541-2197 angelo@upf.br}

\section{Miguel da Silva \\ Rossetto ${ }^{1}$}

orcid.org/0000-0001-6889-7983 miguel.rossetto@upf.br

Recebido em: 3 out. 2019. Aprovado em: 6 jun. 2020. Publicado em: 2 dez. 2020.

\section{(c) (i)}

Artigo está licenciado sob forma de uma licença Creative Commons Atribuição 4.0 Internacional.
Resumo: O artigo argumenta que o conservadorismo moral da "comunidade moral bolsonarista" baseia-se em uma noção fechada e dogmática de mundo, assim como na ideia fundamentalista de ser humano como essência pronta e numa ontologia antropológica hierarquizada. A partir desse passo, recorre-se ao pragmatismo falibilista de Bernstein como referência crítica ao conservadorismo moral autoritário e ao perigo de fechamento do espaço público que ele representa. Na sequência, procura-se mostrar que essa maneira pública e crítica de pensar dá origem a uma noção aberta e plural de mundo e à compreensão da condição do ser humano como indeterminada, condição que contradiz o desejo irracional e desmesurado de onipotência. Conclui-se, por fim, defendendo-se que é o nexo entre mundo aberto e fragilidade humana, no marco de uma ética democrática, que cria as condições propicias para experiências éticas e formativas. Palavras-chave: conservadorismo moral, condição humana, falibilismo, ética democrática

Abstract: This article argues that the moral conservatism of the « Bolsonarian moral community » is based on a closed and dogmatic notion of the world, as well as on the fundamentalist idea of the human being as a ready essence and on a hierarchical anthropological ontology. From this point, Bernstein's fallibilist pragmatism is used as a critical reference to authoritarian moral conservatism and the danger of closing the public space it represents. Next, we aim to show that this public and critical way of thinking gives rise to an open and plural notion of the world and to the understanding of the condition of the human being as indeterminate, a condition that contradicts the irrational and excessive desire for omnipotence. Finally, it concludes that the nexus between open world and human fragility, within the framework of a democratic ethic, creates the conditions conducive to ethical and formative experiences.

Keywords: moral conservatism, human condition, fallibilism, democratic ethics

Resumen: El artículo argumenta que el conservacionismo moral de la «comunidad moral bolsonarista» está basado en una noción cerrada y dogmática de mundo, como también en la idea fundamentalista de ser humano como una esencia preparada y una ontología antropológica jerarquizada. Desde eso, se recurre a un pragmatismo falibilista de Bernstein como referencia crítica al conservadorismo moral autoritario y al peligro de cierre del espacio público que él representa. En la secuencia, es posible percibir que con esa manera pública y critica de pensar surge una noción abierta y plural de mundo y una comprensión de la condición del ser humano como indeterminada, condición que contradice el deseo irracional y desmesurado de omnipotencia. Se concluye, al final, defendiéndose que es un eje entre mundo abierto y fragilidad humana, en el marco de una ética democrática, que crea las condiciones propicias para experiencias éticas y formativas.

Palabras clave: conservacionismo moral, condición humana, falibilismo, ética democrática 
Nossos compromissos e convicções tornam-se mais fortes quando estão imbuídos de deliberação inteligente e postos à prova no debate público. (Bernstein, 2006, p. 116)

Há um clima de apreensão com o governo Bolsonaro. Parece que se está mergulhando num obscurantismo educacional e político que faz o Brasil retroceder a visões de mundo pré-modernas. Por isso, entender os motivos da eleição de Bolsonaro e os traços constitutivos da comunidade moral e religiosa que o sustenta é uma tarefa teórica importante. Não menos importante também é o esforço intelectual de criticá-las, apontando alternativas, sobretudo, do ponto de vista intelectual. Oferecer um diagnóstico da comunidade moral bolsonarista, delineando algumas perspectivas críticas é precisamente $o$ objetivo deste escrito.

Dividimos o ensaio em duas partes. Na primeira, trata-se do diagnóstico propriamente dito, buscando construí-lo com apoio da crítica sociológica de Angela Alonso (2019) à "comunidade moral bolsonarista". A referida critica auxilia a compreender os três pilares que sustentam tal comunidade, a saber: o nacionalismo beligerante, o moralismo hierarquizador e o antielitismo. $\mathrm{Na}$ segunda parte, procura-se criticar a comunidade moral bolsonarista à luz do pragmatismo falibilista defendido por Richard Bernstein (2006). O recurso à interpretação de Bernstein justifica-se, entre outros aspectos, porque sua argumentação a favor da mentalidade falibilista é vertida contra o fundamentalismo conservador e autoritário que pautou a reação do governo Georg W. Bush contra o ataque terrorista desferido às Torres Gêmeas de Nova York, em 11 de setembro de 2001. Desse modo, a maneira falibilista de pensar também se torna recurso apropriado mutatis mutandis para criticar o conservadorismo autoritário inerente à comunidade moral bolsonarista, sobretudo, as pressuposições ontológicas e antropológicas que sustentam sua concepção patriarcal de familia, tomada como modelo de intervenção política no espaço público.

\section{O renascimento do conservadorismo autoritário}

A melhor metáfora para descrever o Brasil da atualidade é a de um trem grande, com máquina potente, mas completamente descarrilhado. Fora dos trilhos, por mais forte que seja, não consegue andar e, sem se mover, perde a sua utilidade, empacando os seus passageiros. A eleição de Jair Messias Bolsonaro contribuiu decisivamente para que o trem descarrilhasse; mas se engana quem pensa que a sua eleição seja a principal causa do descarrilamento. A vitória de Bolsonaro e, com ela, a ascensão ao poder do conservadorismo moral é fenômeno complexo que depende da conjugação de muitos fatores, de natureza econômica e política, os quais são tecidos, ganhando forma especifica pelo modo de ser brasileiro, cultural e religioso. ${ }^{2}$ Sendo assim, o bolsonarismo tornou-se possivel, em grande parte, porque catalisou, dando expressão política, a esse éthôs autoritário que impregna a tradição cultural brasileira. Com o uso das novas e diferentes mídias sociais, Bolsonaro apresentou-se como homem comum, de costumes simples, que vive como todo mundo e, principalmente, que não precisa dedicar-se ao pensamento para resolver os seus problemas, ou seja, um anti-intelectual. Ele mostrou ser desnecessário ter ideias profundas e complexas, sendo suficiente apego familiar forte e crença inabalável em Deus. Desenhando de maneira calculada esse perfil junto ao eleitorado, prometeu acabar com a corrupção e garantir segurança para todos.

Para poder compreender esse acontecimento, há, antes de tudo, um aspecto do contexto social e econômico mais amplo a ser considerado: tudo o que acontece no Brasil, assim como em qualquer outro país do mundo, não ocorre de maneira autônoma e desconectada da ordem mundial neoliberal, a qual impõe um modo de ser econômico e político que gera disputas e tensões sociais inevitáveis, excluindo grupos e nações inteiras em nome da extraordinária e irracional concentração de riqueza nas mãos de poucos. Nessa

\footnotetext{
2 Não se analisará aqui os problemas internos da esquerda brasileira e, especialmente, os erros cometidos pelo governo petista que contribuiram para o ressurgimento do conservadorismo moral e a vitória eleitoral de Jair Bolsonaro.
} 
perspectiva, uma das caracteristicas centrais do neoliberalismo é a supressão do Estado social em nome do Estado empresarial, desobrigando-o juridicamente das suas funções sociais básicas e obrigando-o simultaneamente a ser gerenciado pelos principios (neoliberais) da competição ilimitada, eficiência extremamente racionalizada e lucratividade voraz. Esse modo de ser neoliberal transforma, como investigou detalhadamente Michel Foucault (2008), o sujeito contemporâneo em empreendedor de si mesmo, provocando novas e sofisticadas formas de assujeitá-lo. Reduzido exclusivamente aos seus aspectos econômicos, o empreendedorismo precariza a formação ética do sujeito. O reverso de tudo isso é o aumento crescente do individualismo em detrimento de formas cooperativas e solidárias de vida.

De qualquer maneira, há uma tensão interna no governo Bolsonaro, entre o neoliberalismo radical e o fundamentalismo religioso e moral, que põe permanentemente à prova o governo para enfrentá-lo. O neoliberalismo radical não só prega o Estado mínimo, gerenciado como empresa, sem intervir no funcionamento da economia privada, como também exige flexibilidade cultural e profissional do sujeito empreendedor de si mesmo. Na contramão disso tudo, o fundamentalismo religioso só consegue assegurar valores morais tradicionais, aos moldes da família patriarcal, com base na ordem social cristalizada e na concepção dogmática e fixa de ser humano. Expresso em outros termos, o neoliberalismo exige uma mentalidade moderna que, embora não se proponha a enfrentar a desigualdade social, na miséria e na pobreza humanas, exige flexibilidade e capacidade de adaptar-se às demandas versáteis do mercado de trabalho por parte das novas gerações. Ora, a flexibilidade e o dinamismo do mercado não encontram ressonância na concepção de mundo antimoderna, baseada no patriarcalismo rigidamente hierarquizado e na educação autoritária das novas gerações. Evidencia-se aí, nesse sentido, a base de um conflito mais amplo e profundo entre os grupos apoiadores do governo Bolsonaro que torna praticamente incompativel a relação entre o liberalismo na economia e o conservadorismo nos costumes. Esse conflito torna-se ainda mais claro quando se analisa o moralismo religioso que sustentou decisivamente a emergência do bolsonarismo e a eleição de Jair Bolsonaro à presidência da República.

Em seu ensaio "A comunidade moral bolsonarista", Angela Alonso (2019) analisa aspectos culturais e especificamente morais que estão na base do grupo de sustentação mais próximo de Jair Bolsonaro; tais aspectos também auxiliam a compreender a origem do presidente eleito e alguns de seus propósitos. Em síntese, o foco no aspecto moral do grupo torna-se importante para compreender o caráter conservador e autoritário que marca historicamente parcelas expressivas da tradição cultural brasileira e o peso que certo pensamento religioso desempenha, enquanto cimento ideológico, no fortalecimento da forma de poder dominadora e excludente. O próprio lema da campanha presidencial "O Brasil de todos. Deus acima de tudo" e a primeira manifestação de Bolsonaro, depois de eleito, invocando a Deus e solicitando ao pastor Magno Malta que fizesse a oração são indicativos da presença direta de suas convicções religiosas em suas ideias politicas. Vê-se, aqui, num piscar de olhos, o esboroamento dos ideais republicanos, entre eles, a laicidade do Estado, como bandeira arduamente conquistada pela tradição iluminista moderna. O forte apelo à religião feito, principalmente, como cruzada ideológica contra o "marxismo cultural", traz obviamente consequências para a concepção de educação e, por conseguinte, para o direcionamento de políticas educacionais públicas.

Segundo Ângela Alonso (2019), a comunidade moral bolsonarista é constituida pelo tripé nacionalismo beligerante, moralismo hierarquizador e antielitismo. Considerando o peso que esse tripé desempenha na visão de mundo do grupo de Bolsonaro e a influência que exerce em suas decisões políticas, cabe reconstruir com mais detalhes as características de cada um deles. O nacionalismo é tema inerente à história das nações e cada país envolve-se com ele a sua própria maneira. Na história do Brasil recente, a 
campanha nacional pelas eleições diretas, que desagua, posteriormente, nas conquistas sociais importantes expressadas pela Constituição Federal de 1988, faz amplo uso do hino nacional e das cores da bandeira nacional para expressar o sentido patriótico de luta por democracia e justiça social. De outra parte, vários movimentos políticos, alguns deles liderados por setores da elite brasileira, iniciados em 2011 e que culminam na posterior eleição de Jair Bolsonaro à Presidência da República, também fazem uso, obviamente por razões diferentes, de símbolos nacionais característicos. Segundo Alonso (2019), especificamente no caso de Bolsonaro, a sua campanha eleitoral acentuou incisivamente a simbologia patriótica, alicerçando a sua propaganda em três binarismos: nacionalismo versus globalismo; pátria como negação de classe e, por último, pátria versus partido. No que se refere ao primeiro binarismo, ele já antecipa algumas diretrizes do futuro Ministério das Relações Exteriores, privilegiando a diplomacia servil ao governo norte-americano de Donald Trump em detrimento dos paises que são inimigos do próprio governo americano.

De sentido moral e político mais claro são, contudo, os dois outros binômios. A negação de classe, caracteristica do segundo binômio, feita com o propósito de aproximar ricos e pobres, tem o efeito destrutivo de encobrir as enormes injustiças sociais que marcam historicamente o País. A pregação da falsa homogeneidade encobre também o pluralismo cultural das diferentes formas de vida, característico das sociedades complexas contemporâneas, negando igualmente questões de gênero e raça. Diante disso, a única igualdade reconhecida é aquela que subordina todos ao poder institucional, sobretudo militar, e à divindade. Desse modo, Forças Armadas e Deus são exemplos supremos de entidades inquestionáveis, que exigem obediência irrestrita das pessoas. Em sintese, a ignorância em relação aos conflitos entre grupos sociais com interesses antagônicos e aos problemas relacionados com as questões de gênero e raça é a evidência clara do fechamento perigoso do espaço público, deixando de concebê-lo como ambiente legítimo de manifestação e debate crítico sobre o pluralismo cultural e, por conseguinte, do caráter falivel das próprias crenças e convicções humanas. Ora, a certeza inabalável de certas crenças e valores e a tentativa de impô- las autoritariamente às diferentes formas de vida certamente põe em risco a democracia.

O terceiro binômio pátria versus partido aproxima, por sua vez, liberais e conservadores em nome da luta pelo livre mercado, pela anticorrupção e pela segurança pública. Junto com a crítica ao partido, vem a descrença nos políticos em geral e nos poderes da República, atribuindo a solução de problemas a grupos especializados, de espírito patriótico, representados especialmente pelas Forças Armadas. Isso explica, então, a militarização do governo, a qual, no dizer de Alonso (2019, p. 54), "coaduna com a comunidade moral bolsonarista, que vê as Forças Armadas como encarnando a nação, acima das clivagens intestinas. Sua supremacia simbólica facultaria moderar conflitos e intervir nas crises". O próprio capitão Bolsonaro seria o exemplo mor desse espírito na medida em que se dispõe a transportar para o Estado o mesmo principio disciplinador que rege a tropa, ou seja, a obediência irrestrita à hierarquia e a mesma forma violenta de combate que caracteriza a guerra, cujo objetivo principal é a derrota do inimigo, mesmo que, para isso, seja necessária a sua eliminação física. Sendo assim, a politica, concebida como guerra, deixa de ser a arte do convencimento movida pela força das palavras, transformando-se no uso violento do poder, visando à destruição do inimigo. Em síntese, o terceiro binômio do nacionalismo beligerante concebe a obediência irrestrita ao poder hierárquico e a resolução de conflitos pela força (violência) como formas genuínas de assegurar a vitória da pátria contra seus inimigos.

Convém ressaltar que o nacionalismo beligerante da comunidade moral bolsonarista, ao defender a guerra violenta como forma de fazer política e, por conseguinte, como forma de aniquilamento do inimigo, distancia-se do sentido grego clássico de guerra como exercício da formação ética do sujeito. O espírito guerreiro do soldado, cultivado mediante diferentes formas de exercí- 
cio de si, dá origem à coragem como uma das virtudes cardinais que orienta o exercício cidadão na polis (Gros, 2009). De outra parte e nesse mesmo contexto, o surgimento do moderno estado democrático de direito dispensa o emprego de formas violentas de fazer política, uma vez que a própria política passa a ser concebida como a arte do convencimento negociado com base na força do melhor argumento. Desse modo, a única força admitida, que não é obviamente a força física violenta, é o poder do discurso argumentativo enraizado no livre exercício da ação comunicativa (Habermas, 1998). A participação de todos, ouvindo uns aos outros, tomando a palavra e manifestando as suas ideias de maneira racionalmente justificada, é traço indispensável da formação democrática do espaço público. Conforme veremos adiante, a força da democracia repousa no debate público critico, diferenciando-se obviamente de crenças sustentadas pelo irracionalismo religioso e por paixões ideológicas discriminadoras e excludentes.

No que se refere ao moralismo hierarquizador, segundo aspecto da comunidade moral bolsonarista, o núcleo repousa na defesa intransigente da familia patriarcal, concebendo-a como viga mestra da organização social. O fortalecimento da moral privada conservadora, tornando-a eixo de intervenção no espaço público, faz esboroar a fronteira moderna entre privado e público, impondo retrocesso visivel a valores tradicionais antimodernos. Em que consiste a familia patriarcal defendida pela comunidade moral bolsonarista e como ela torna-se referência de atuação política no espaço público? Quais são os indícios empíricos que comprovam essa diretriz moral? A familia patriarcal tem, no seu centro, o comando autoritário e inquestionável do homem e o papel subserviente da mulher, cujo campo de atuação deve limitar-se prioritariamente à esfera familiar: como rainha do lar, a mulher deve cuidar da casa, do marido e dos filhos. Pressupõe-se, aqui, como crença naturalizada, a superioridade inata do masculino sobre o feminino, garantindo, assim, ao homem o direito de mando inquestionável. Portanto, com base no pressuposto dessa superioridade natural, a mulher (esposa) deve obediência ao homem (marido), mesmo que, para isso, ele tenha que recorrer à violência, principalmente quando vê a sua autoridade contestada. ${ }^{3}$

Angela Alonso comprova empiricamente o patriarcalismo autoritário, sedento de obediência irrestrita, como algo que existe no seio da própria família Bolsonaro, evidenciado pelo comportamento dos filhos do capitão, Flávio e Eduardo. O primeiro, senador eleito pelo Estado do Rio de Janeiro e denunciado, posteriormente, no envolvimento com corrupção de dinheiro público e de vinculo com grupo miliciano, postou em seu Facebook, na época da campanha, o clipe "Proibidão do Bolsonaro", cuja letra deixa-se explicar por si mesma: "pras feministas, ração na tigela/ As mina de direita são as top mais bela/ Enquanto as de esquerda tem mais pelo que cadela" (Alonso, 2019, p. 58). Eduardo Bolsonaro, eleito deputado federal por São Paulo, disse à sua ex-namorada, em abril de 2018: "Depois reclama que apanhou. Você merece mesmo. Abusada. Tinha que ter apanhado mais para aprender a ficar calada. Mais uma palavra e eu acabo com você" (Alonso, 2019, p. 59). Contudo, esse comportamento machista e agressivo vem de berço, uma vez que o próprio pai, como se tornou amplamente conhecido, dirigiu à deputada Maria do Rosário as seguintes palavras ofensivas: "É muito feia. Não te estupro porque você não merece" (Alonso, 2019, p. 59).

A comunidade moral bolsonarista prolonga, de diferentes formas, esse núcleo duro da moral privada conservadora para a esfera pública. $\mathrm{O}$ primeiro fronte de ataque é as escolas e as universidades, apoiando o Movimento Escola Sem Partido. Como as escolas e as universidades estão tomadas por professores "esquerdistas" - este é o diagnóstico bolsonarista -, que pregam o comunismo, a igualdade de gênero e o fim das religiões, pondo, assim, em cheque a obediência hierárquica aos bons costumes, compete à família patriarcal, constituida por sangue e afeto, retomar

\footnotetext{
3 Em seu estudo O direito da liberdade (Das Recht der Freiheit) Axel Honneth (2013) delineia os traços da familia moderna opondo-os à familia patriarcal.
} 
as rédeas da educação. A educação tradicional sempre atribuiu ao professor poder irrestrito dentro da sala de aula, delegando ao aluno posição passiva, de obediência silenciosa. Baseando-se no binômio transmissão-memorização, tal educação defende a postura disciplinarmente rígida do professor e a passividade do aluno como condição do ensino e da aprendizagem. Característico aí, nesse contexto, é a relação pedagógica hierarquicamente verticalizada, baseada na crença autoritária de que é o professor quem ensina, cabendo ao aluno aprender pela obediência irrestrita à autoridade do mestre.

Contudo, como no cenário brasileiro atual da educação formal, a maioria dos professores está tomada pela maléfica "ideologia esquerdista", os pais precisam assumir com mais energia a sua responsabilidade familiar, orientando os filhos para procederem "adequadamente" na sala de aula, protegendo-se contra os disparates ideológicos dos professores e do seu comportamento excessivamente liberalizante. A consequência nefasta disso parece estar clara, como alerta Alonso (2019, p. 60): "Para proteger a liberdade dos pais de produzir suas ideias, os sem-partido obstam a dos filhos de eleger as próprias, a partir da variedade oferecida pela escola". O Escola Sem Partido, ao defender a intervenção externa autoritária dos pais na escola, vai exatamente na contramão da tradição democrática que concebe a escola como espaço livre da prática genuína do ócio estudioso. Com o seu jargão conservador, em nome da defesa intransigente da ordem e dos bons costumes, o Escola Sem Partido, ao delegar autoridade e verdade exclusiva aos pais, bloqueia a possibilidade do pensar como tarefa vital da escola, principalmente, como exercício estudioso que enobrece a condição de ser aluno e professor. Trata-se de uma escola que não pode questionar ou contrariar valores e conteúdos oriundos da família. O sentido social da educação é empobrecido mediante o discurso acerca do papel da escola voltado à aprendizagem dos "valores tradicionais" da familia e da moralidade e onde cabe ao professor realizar o seu trabalho de forma neutra e técnica. (Gonzales \& Costa, 2018). Nesse contexto, todo o empenho para aprovar o projeto de lei Escola Sem Partido visa, em última instância, conforme argumenta o filósofo José Arthur Giannotti (2019, p. 172), "retirar do docente seu caráter exemplar, daquele que sabe pensar, isto é, colocar-se apropriada e pessoalmente diante de novas situações".

Desse modo, o Escola Sem Partido, retrocedendo à concepção tradicional antimoderna de educação, simplesmente desconsidera os mais altos ideias educacionais modernos formulados, entre outros, no cenário alemão do século XIX, por Johann Friedrich Herbart e, no cenário norte-americano do século $X X$, por John Dewey. Herbart, como formulador da teoria da instrução educativa, atribui à escola e à liderança intelectual do professor dentro da sala de aula papel indispensável na formação do autogoverno pedagógico. Com o olhar focado nos problemas educacionais de sua época e com visão alargada de futuro, percebeu que os tempos modernos exigiam o desenvolvimento de todas as capacidades humanas em todas as direções, isto é, a formação humana baseada na multiplicidade do interesse (Herbart, 1965). ${ }^{4}$

John Dewey (2008), por sua vez, criou o laboratório escola no interior da Universidade de Chicago com base na convicção de que o ambiente escolar autônomo é decisivo para fomentar experiências educacionais livres e democráticas. Da mesma forma que Herbart, ele concebia a posição ativa do aluno como aspecto indispensável do processo educativo, cabendo ao professor, como guia intelectual, tomar a experiência de mundo do aluno como ponto de partida de seu ensino, buscando elevá-la intelectualmente. Portanto, esses dois pedagogos clássicos consideram como nortes da educação democrática e humanizadora o espaço escolar autônomo, a posição ativa do aluno e a formação intelectual consistente do professor. De maneira alguma, negam o papel educativo indispensável da familia, mas limitam claramente o âmbito de interferência

\footnotetext{
4 O alcance e a atualidade da educação democrática e humanizadora de Herbart certamente estão na origem da fundação, em 2005 da Internationale Herbart Gesellschaft (https://www.herbart-gesellschaft.de recuperado em 30 de setembro de 2019).
} 
dela na escola, desautorizando qualquer forma de intervenção autoritária dos pais no trabalho formativo do professor. Em sintese, para ambos, a dimensão plural, autônoma e formativa da escola pressupõe a relação reciproca e de respeito mútuo entre professor e aluno e isso, obviamente, conduz à crítica a qualquer forma de obediência hierarquizada, assentada na relação vertical, autoritária e excludente entre seres humanos.

Por fim, o antielitismo, como já afirmado anteriormente, é o terceiro tripé da comunidade moral bolsonarista. O antielitismo tem como propósito vender a imagem do presidente Jair Bolsonaro e daqueles que o cercam como seres humanos simples, que levam uma vida comum, nada sofisticada; tudo deve ser simples, como comida, vestimenta e o relacionamento entre as pessoas. Querem fazer crer, com isso, que se pode dirigir o País e tomar decisões políticas complexas sem precisar conhecer a fundo a realidade brasileira e, por isso, sem precisar estudar, refletir e formar a capacidade de julgamento crítico. Portanto, a faceta mais evidente e talvez mais desastrosa do antielitismo é o seu anti-intelectualismo. Trata-se da reação contra a teoria e as diferentes formas de pensamento elaborado e o descrédito de seu auxílio indispensável para o conhecimento e a resolução de problemas humanos e sociais. 0 próprio presidente Bolsonaro mostra-se um sujeito pouco afeito aos livros e à leitura, com exceção da Biblia, e da companhia de intelectuais, salvo a presença constante de Olavo de Carvalho, o seu mentor e guru intelectual. Após analisar o vídeo "Sr. Mito", Alonso (2019) tece o seguinte comentário:

Bolsonaro se apresenta como brasileiro médio, pai de familia, trabalhador, sem tempo, dinheiro ou paciência para os maneirismos dos cultos. Seu lazer é com a familia e os amigos, ir à praia, ao shopping, ao futebol e, quem sabe, a Miami. (p. 63)

Dessa forma, investindo na estética do improviso, enaltece o homem comum, fazendo a sua fala coloquial combinar autoridade e emoção. Contudo, essa imagem do homem simples e comum contradiz flagrantemente a outra, a do patriarca soberano e autoritário, que, ungido pela benção do Todo
Poderoso, torna-se a fonte terrena da obediência hierárquica, verticalizada autoritariamente.

O reconhecimento ao "poderio" intelectual de um figura como Olavo de Carvalho é evidência da combinação entre antielitismo e anti-intelectualismo. Tal combinação deixa claro o que se avizinha no horizonte educacional próximo, ou seja, a guerra ideológica da comunidade moral bolsonarista contra o "marxismo cultural", o qual, segundo Carvalho, toma conta do cenário educacional brasileiro. No que se refere à postura intelectual de Olavo de Carvalho, Alonso (2019, p. 65) afirma: "Não tem teorias próprias, desclassifica as alheias - com predileção pela teoria gramsciana da hegemonia. Carece de conceitos, constrói-se na antítese do discurso inimigo", ou seja, o guru intelectual de Bolsonaro carece de conceitos próprios ou manuseia-os confusamente, sem senso analítico, vê a sua reputação de pensador comprometida. De outra parte, construir-se somente na antitese do pensamento inimigo, sem lhe reconhecer algum tipo de mérito, compromete a sua honestidade intelectual, servindo apenas, bizarramente, como ideólogo da maneira dogmática e antimoderna de pensar.

Em sintese, com o auxilio da análise sociológica minuciosa da comunidade moral bolsonarista, construida por Angela Alonso, é possivel ver a profundidade do retrocesso cultural, político e educacional à época pré-moderna, que representa a ocupação do Planalto pelo pensamento conservador autoritário. A democracia está em risco, primeiramente, porque, para o nacionalismo beligerante, é imprescindivel a postura de guerra contra o inimigo baseada na obediência irrestrita à hierarquia verticalizada e autoritária. Em segundo lugar, porque o moralismo hierarquizador, ao desconsiderar a distinção moderna entre moral privada e atuação no espaço público, transpõe perigosamente para o espaço público os valores ultraconservadores do patriarcalismo familiar. Por fim, a democracia expõe-se ao risco quando é sufocada pela predominância do anti-intelectualismo, o qual, ao simplificar extraordinariamente o diagnóstico dos problemas e a busca por soluções deles, subestima a 
capacidade de pensar dos brasileiros e brasileiras e da inteligência humana em geral. Sufoca, com isso, em última instância, a própria capacidade humana de perguntar, ou seja, a possibilidade democrática de exercitar livremente a capacidade de pensar e julgar por conta própria. Ancorada no tripé anteriormente analisado, a comunidade moral bolsonarista mostra uma visão de mundo antimoderna e, regredindo à época pré-moderna, desconhece o grande mote do próprio esclarecimento moderno, ou seja, a sapere aude (ousar saber) como núcleo referencial da maioridade humana, social, ética e política.

\section{Pragmatismo falibilista e ética democrática}

O quadro desenhado anteriormente amedronta, parecendo jogar o País de volta ao obscurantismo anterior às Luzes. Contudo, não há outra saída senão a coragem de recomeçar e, com o auxilio do pensamento crítico, retomar intelectualmente perspectivas históricas que foram simplesmente apagadas do mapa pela mão do conservadorismo autoritário, ressurgido com muito ânimo no Brasil recente. Neste sentido, nada mais urgente e atual do que intensificar o diálogo crítico com a tradição das teorias educacionais clássicas - e este é um dos principais papeis da filosofia da educação sabendo reter delas o que é interessante para pensar a nossa atualidade. Na segunda parte deste ensaio, faremos um pequeno exercício de diálogo reconstrutivo da tradição do pragmatismo americano, inspirando-nos no livro O abuso do mal, de Richard J. Bernstein. Esse recurso ao livro de Bernstein cumpre dupla finalidade: primeiro, porque o autor, ao escrevê-lo logo depois do ataque terrorista de 11 de setembro de 2001, feito às Torres Gêmeas de Nova York, critica o fundamentalismo que está subjacente não só à ação dos terroristas, mas principalmente à reação autoritária do governo Georg W. Bush. O fundamentalismo torna-se inimigo da democracia porque concebe binariamente o mundo e, ao dividi-lo em dois grupos, um supostamente do bem e o outro seguramente do mal, separa rigidamente os seres humanos entre bons e maus. A segunda finalidade refere-se ao modo como Bernstein acentua a dimensão falibilista do pragmatismo, pondo-a como base filosófica de crítica ao fundamentalismo e, ao mesmo tempo, como maneira de pensar própria da mentalidade democrática. A maneira falibilista de pensar torna-se, então, uma boa referência para criticar o conservadorismo autoritário inerente à comunidade moral bolsonarista.

A comunidade moral bolsonarista baseada na familia patriarcal, com a sua hierarquia rigidamente verticalizada, é fruto de mentalidade epistemologicamente fechada e dogmática, ficando muito aquém da revolução copernicana na maneira de pensar e da postura falibilista contemporânea resultante dela. Ao investigar as condições de uso da razão pura, esforçando-se para mostrar os seus alcances e os seus limites, Kant (1997) desferiu golpe fatal ao dogmatismo metafísico, abrindo espaço para formas falibilistas contemporâneas de pensar. Não é por acaso que Charles S. Peirce (1983), considerado pai do falibilismo contemporâneo, confessou de bom grado ter lido sistematicamente, frase por frase e parágrafo por parágrafo, durante dois anos, a Crítica da Razão Pura. A profundidade filosófica e científica de Peirce influenciou todos os pragmatistas posteriores, especialmente John Dewey.

Em que consiste propriamente o falibilismo pragmatista? Em O abuso do mal, Richard Bernstein define-o da seguinte maneira: "O falibilismo é a crença de que qualquer reivindicação de conhecimento ou, em geral, qualquer reivindicação de validez - incluídas as reivindicações morais e políticas - são passiveis de análise, modificação e criticas permanentes" (Bernstein, 2006, p. 55). Essa breve definição contém três ideias antagônicas à mentalidade fundamentalista que sustenta o conservadorismo moral. Primeiramente, afirma que toda a crença precisa estar aberta à crítica, isto é, dispor-se a ouvir o contraditório e o diferente, suspendendo a sua arrogância inicial de que possui a última palavra. Em segundo lugar, a crença só pode tornar-se verdadeira - mas, nesse caso, trata-se de verdade provisória -, enquanto resistir ao crivo da crítica baseada em bons argumentos. 
Por fim, a abertura da crença à crítica provoca o seu próprio autoexame. Examinar os seus próprios pensamentos no confronto permanente com posições contrárias e diferentes aos seus, que se formam no debate público, é tarefa autocorretiva indispensável do espaço do viver junto formado democraticamente. É por isso que não existe, sob a ótica do pragmatismo falibilista, certeza absoluta e nem última palavra sobre as coisas. Esse modo falibilista de pensar é justamente o que conduz Peirce à ideia democrática de ciência baseada na comunidade de investigadores, concebendo-a como lugar de desmistificação das certezas absolutas e, simultaneamente, como forma de validação de crenças justificadas, resultantes da força do melhor argumento. ${ }^{5}$

Em outra passagem de seu texto, dessa vez um pouco mais extensa, Richard Bernstein põe ênfase ainda maior na disposição do ser humano de submeter as suas crenças à crítica pública:

Uma orientação falibilista requer a disposição genuina para provar nossas ideias em público e escutar com atenção aqueles que as criticam. Precisa da imaginação para formular novas hipóteses e conjecturas e submetê-las a uma rigorosa verificação e critica públicas por parte da comunidade de investigação. O falibilismo necessita de alta tolerância à incerteza e o valor de revisar, modificar e abandonar nossas crenças mais caras quando estas têm sido refutadas. (Bernstein, 2019, p. 56)

Há dois traços distintivos do falibilismo nessa passagem que são nucleares da crítica às crenças dogmáticas, ao mesmo tempo que também se tornam pilares do pensamento democrático. 0 primeiro traço, já analisado na passagem anterior, refere-se à disposição do ser humano de submeter as suas crenças à crítica pública. Não se trata aqui, obviamente, de disposição inata, pois o ser humano não nasce apto a submeter as suas ideias ao crivo alheio. Pelo contrário, há muito mais a propensão, por diferentes razões, principalmente de ordem psicológica, de fechar-se em suas próprias crenças, evitando expô-las publicamente. Diante dessa "indisponibilidade" à exposição pública, torna-se tarefa educacional importante criar o espaço público de formação do sujeito para o exercício da crítica. É precisamente a partir desse contexto que se compreende melhor a preocupação permanente de John Dewey pelo nexo estreito entre a educação e a democracia, concebendo-o nos moldes de um círculo virtuoso: a formação do pensamento falibilista (crítico) depende do espaço público, o qual, por sua vez, só pode ser dinamizado democraticamente pelo exercício permanente da crítica. É a educação (enquanto formação) que dinamiza, dando vida a esse círculo virtuoso.

O segundo traço do falibilismo recai sobre a noção de incerteza como pressuposto da crítica e, por conseguinte, como contrário à certeza absoluta. John Dewey mostra, em várias passagens de sua obra, como o falibilismo epistemológico está alicerçado na noção de mundo (ontologia cosmológica) e de ser humano (antropologia filosófica) que cria as condições iniciais indispensáveis à própria educação democrática. Em outros termos, pressuposições ontológicas e antropológicas sustentam a mentalidade falibilista propícia à formação de experiências formativas democráticas. Primeiro, no que se refere à sua noção de mundo, cabe extrair uma bela passagem de um de seus textos, bem ilustrativa, igualmente citada por Bernstein:

\begin{abstract}
O ser humano se dá conta de que vive em um mundo aleatório; sua existência implica uma aposta, para dizer sem rodeios. O mundo é um cenário de risco; é incerto, instável, assombrosamente instável. Seus perigos são irregulares, inconstantes, não confiáveis em relação aos seus estados e momentos. O território, o ser humano, a perda das coisas, a enfermidade, a morte, a derrota na batalha estão sempre por perto, logo ali na esquina, como também estão a abundância, a fortaleza, a vitória, o festival e a canção. A sorte é proverbialmente boa e má em sua distribuição. (Dewey, 1981, p. 278 como citado em Bernstein, 2006, pp. 69-70)
\end{abstract}

Muitas características dessa ontologia cosmológica, descritas bem nos termos de um estoicismo existencial, podem ser vertidas criticamente contra o mundo fechado do conservadorismo moral. Antes de tudo, não é parte desta ontologia cosmológica, o mundo binário, dividido de manei- 
ra maniqueista entre bem e mal, pois alega que maldade e bondade não são exclusividades de um único sujeito ou grupo. De outra parte, tanto o risco como a instabilidade assombrosa nascendo da permanente suspeita reflexiva do sujeito sobre o real e de sua deliberação inteligente sobre o curso de sua própria ação põem em cheque certezas absolutas. O risco, por exemplo, nasce da incapacidade humana de dominar por inteiro as relações que os seres humanos mantêm entre si e com as coisas. A impossibilidade de tal domínio gera instabilidade e, assombrado, o ser humano vê as suas certezas esfarelarem-se, tendo de reconstrui-las em novas bases. Por outro lado, do risco também pode brotar a fortaleza, ou seja, a armadura que oferece ao sujeito a possibilidade de cultivar o assombro diante da instabilidade avassaladora. Como se vê, bem ao contrário do mundo fechado, previamente determinado e com crença inabalável na existência do final feliz, trata-se do mundo aberto, plural, instável, cuja finalidade movediça depende da deliberação inteligente no espaço público constituido pelo debate crítico.

Mundo aberto, plural e instável é co-originário da indeterminação da condição humana. Em Democracia e Educação, principal escrito educacional da tradição pragmatista e uma das principais obras educacionais da pedagogia contemporânea, John Dewey define a indeterminação humana como plasticidade (plasticity), colocando-a na base do nexo estreito que estabelece entre educação e democracia. Nas próprias palavras de Dewey: "A disposição especíica de um ser imaturo para o crescimento constitui sua plasticidade" (Dewey, 2008, p. 49). O que significa plasticity? Tal conceito tem origem na tradição clássica do esclarecimento moderno, especialmente na noção rousseauniana de perfectibilidade (perfectibilité). Rousseau narra, no Segundo Discurso ${ }^{6}$, com estilo literário embriagante, como da liberdade origina-se a perfectibilidade (Rousseau, 2003), tornando-a, na sequência de seu pensamento, uma categoria chave da formação humana. Ele concebe a perfectibilidade como capacidade humana de formar outras capacidades. Se não nascemos prontos, possuimos ao menos muitas capacidades que nos tornam diferentes do que somos, sendo a capacidade de aperfeiçoar-se constantemente (a perfectibilidade) precisamente a força que movimenta todas as outras capacidades. Ora, essa capacidade infinita do ser humano de aperfeiçoar-se é o que o torna um ser educável, ou seja, com capacidade de educar e deixar-se educar, educando-se a si mesmo (autoeducação). Colocando-se como fonte e origem da educabilidade humana, a perfectibilidade faz de Rousseau o pai da tradição pedagógica alemã da Bildsamkeit, influenciando nitidamente autores como Kant e Herbart.7

Desse modo, liberdade e perfectibilidade, profundamente amalgamadas entre si, constituem, então, a condição humana. Como tal condição é pensada, no Segundo Discurso, pelo registro da gênese histórica, a liberdade é o resultado daquilo que o próprio ser humano faz de si mesmo e dos outros, na vida em sociedade, e a perfectibilidade é a grande capacidade, "capacidade das capacidades", que torna possivel o "fazer de si mesmo" e o "fazer dos outros". A ação acontecendo na história, movendo-se pela liberdade e perfectibilidade, abre ao ser humano a possibilidade de escolha, inclusive a de não mais seguir uma teleologia fixa e fechada, que the é imposta de fora. O importante a destacar é que a historicidade da condição humana impede de prever com certeza absoluta os acontecimentos futuros. Ora, é a impossibilidade de antecipar-se com certeza absoluta aos acontecimentos vindouros que constitui a indeterminação humana, nocauteando, assim, o próprio desejo irracional e perigoso por onipotência, materializado, como Rousseau mostrou exaustivamente no Émile, no amor próprio envenenado. ${ }^{8} \mathrm{O}$ reconhecimento da fragilidade da condição humana é decisivo para combater o amor próprio envenenado, crian-

\footnotetext{
Abreviatura estandarte da obra Discurso sobre a origem e os fundamentos da desigualdade entre os homens.

Herbart, juntamente com Rousseau, certamente foi um dos autores que mais influenciaram o pensamento pedagógico de John Dewey Sobre a recepção que Dewey faz do pensamento de Herbart, ver a excelente coletânea de ensaios organizada por Klaus Prange (2014).

8 Para uma interpretação atual detalhada do pensamento de Rousseau na perspectiva da educação do amor próprio, ver Frederick Neuhouser (2008) e Claudio A. Dalbosco (2016).
} 
do as condições para o viver ético, autêntico e transparente na República de iguais entre iguais. Como resultado do processo educativo iniciado na infância, o reconhecimento da fragilidade torna possivel experiências formativas capazes de colocar educador e educando na situação concreta de respeito reciproco.

Esse pano de fundo da pedagogia rousseauniana influencia o sentido formativo atribuido por Dewey à plasticidade da condição humana. O ser humano é um ser plástico, flexivel e maleável, que vive em um mundo incerto e cheio de riscos, sofrendo muitas metamorfoses ao longo de sua vida; precisamente por isso, ele deixa-se formar ao mesmo tempo em que forma e autoforma-se. Dewey (2008) coloca - e esta é sua tese antropológica de fundo - a plasticidade na base de sua concepção de educação como crescimento. Se for levado a sério esse pensamento, tem-se que admitir que a educação é muito mais do que mero treinamento, visando à adaptação das novas gerações à ordem social estabelecida. Como autoformação, ela implica o processo criativo, ou seja, a capacidade humana de desenvolver múltiplas capacidades, nas mais diferentes direções. No contexto da teoria deweyana da instrução, considerando o seu vínculo estreito com a democracia, trata-se de desenvolver capacidades que apontem na direção da cooperação solidária e, portanto, de formas cooperativas de vida. A teoria deweyana da instrução pressupõe, então, como premissa de fundo, a articulação da condição ativa participante do ser humano com experiências formativas que possibilitem emergir a simpatia social como sentimento que une e agrega os seres humanos entre si, tornando-os dispostos à vida em comum. Por isso, a democracia é, para ele, antes de tudo, um valor ético e somente por sê-la é que também se torna forma política de vida.

Outra passagem do texto de Bernstein resume bem o nexo entre falibilismo crítico, baseado em boas razões, espaço público democrático e defesa da justiça:

Nosso profundo compromisso com as causas justas se vê fortalecido e intensificado quando estamos preparados para justificá-las mediante recurso a razões e provas sujeitas ao debate público, aberto e crítico. Isso é essencial para uma democracia que verdadeiramente valoriza a liberdade. (Bernstein, 2006, p. 116)

Em sintese, a postura falibilista torna possivel pensar o vínculo estreito entre abertura e transitoriedade do mundo e a indeterminação da condição humana. Ambos, mundo aberto e condição humana indeterminada, constituem o pano de fundo do debate público, aberto e crítico, fortalecendo, como afirma Bernstein, a nossa responsabilidade pelas causas justas. Não é, portanto, do conservadorismo moral, baseado na mentalidade fundamentalista fechada e dogmática, que brota a sensibilidade para a pluralidade de formas humanas de vida e a disposição de luta pela justiça.

\section{Considerações finais}

Na primeira parte do ensaio, baseando-nos de perto no diagnóstico sociológico de Angela Alonso, investigamos alguns traços morais da comunidade bolsonarista. Procuramos argumentar que seu conservadorismo moral se baseia na noção fechada e dogmática de mundo, a qual pressupõe, por sua vez, a ideia fundamentalista de ser humano como essência pronta, com finalidade previamente determinada e dirigida por forças externas e superiores. Também esclarecemos que o seu conservadorismo moral advém de uma ontologia antropológica extremamente hierarquizada que defende a superioridade de alguns seres humanos em relação a outros. Assumimos, como núcleo argumentativo, que é essa propensão humana doentia e irracional à superioridade que justifica a hierarquia autoritariamente verticalizada da familia patriarcal, naturalizando a superioridade masculina em relação à feminina e, por conseguinte, do marido em relação à mulher.

Na segunda parte do ensaio, tendo como base a interpretação de Richard Bernstein, tomamos o pragmatismo falibilista como referência crítica ao conservadorismo moral autoritário e o enorme perigo de fechamento do espaço público que ele representa. Consideramos como núcleo do falibilismo a postura reflexiva baseada no debate 
público, aberto e crítico. Na sequência, mostramos que essa maneira pública e crítica de pensar dá origem à noção aberta e plural de mundo, concebendo-o em sua dimensão de risco e instabilidade permanente. A essa instabilidade assombrosa do mundo associa-se diretamente a condição indeterminada do ser humano, revelando o quanto a fragilidade humana contradiz frontalmente o desejo irracional e inflamado de onipotência. A moral privada conservadora, baseada na propensão perigosa à onipotência, quando transposta para o mundo público, transforma-se em governo autoritário, empobrecendo a condição humana e tornando quimera vã as causas justas.

Concluímos, por fim, argumentando que o nexo estreito entre mundo aberto e fragilidade humana cria as condições propícias para experiências éticas e formativas que solidificam democraticamente o espaço humano e social do viver junto. Desse modo, é a busca constante pela validação pública e crítica de nossas ideias, e não o seu ofuscamento no fundamentalismo dogmático e retrógado do mundo fechado, que legitima democraticamente os anseios, profundamente humanos, por liberdade e justiça social.

\section{Referências}

Alonso, A. (2019). A comunidade moral bolsonarista. In VÁRIOS AUTORES. Democracia em risco? 22 ensaios sobre o Brasil Hoje. (pp. 52-70). São Paulo: Companhia das Letras.

Apel, K.-O. (1993). Transformation der Philosophie. Band 2: Das Apriori der Kommunikationsgemeinschaft. Frankfurt am Main: Suhrkamp.

Bernstein, R. J. (2006). El abuso del Mal. La corrupción de la politica y la religión desde el 11/9. Buenos Aires: Katz Editores.

Dalbosco, C. A. (2016). Condição humana e educação do amor próprio em Jean-Jacques Rousseau. São Paulo: Edições Loyola.

Dewey, J. (2008). The Middle Works, 1899-1924: Volume 9: Democracy and Education. Illinois: Southern Illinois University Press.

Foucault, M. (2008). Nascimento da biopolítica. São Paulo: Martins Fontes.

Gianott, J. A. (2019). Savonarolas oficiais. In VÁRIOS AUTORES. Democracia em risco? 22 ensaios sobre o Brasil Hoje. (pp. 164-174). São Paulo: Companhia das Letras.
Gonzalez, J. A., \& Costa, M. C. C. (2018, December). Neoliberalismo, neoconservadorismo e educação: o movimento "Escola sem Partido" para além do projeto de lei. Quaestio, 20(3), 551-565. Recuperado de http://periodicos.uniso.br/ojs/index.php/quaestio/ article/view/3248. doi: https://doi.org/10.22483/ 2177-5796.2018v20n3p551-565.

Gros, F. (2009). Estados de violência. Ensaio sobre o fim da guerra. Aparecida, SP: Editora Ideias \& Letras.

Habermas, J. (1998). Faktizität und Geltung. Beiträge zur Diskurstheorie des Rechts und des demokratischen Rechtsstaats. Frankfurt am Main: Suhrkamp.

Herbart, J. F. (2013). Pädagogische Schriften. Zweiter Band: Allgemeine Pädagogik, aus dem Zweck der Erziehung abgeleitet (1806). Herausgegeben von Walter Asmus. Düsseldorf/München: Verlag Helmut Küpper Vormals Georg Bondi.

Honneth, A. (2013). Das Recht der Freiheit. Grundriß einer demokratischen Sittlichkeit. Frankfurt am Main: Suhrkamp.

KANT, I. (1997). Critica da Razão Pura. (4 ed.). Lisboa: Fundação Calouste Gulbenkian.

Melo, C. (2019). A marcha brasileira para a insensatez. In VÁRIOS AUTORES. Democracia em risco? 22 ensaios sobre o Brasil Hoje. (pp. 211-229). São Paulo: Companhia das Letras.

Neuhouser, F. (2008). Rousseau's Theodicy of Self-Love. Evil, Rationality, and the Drive for Recognition. New York: Oxford University Press. doi: https://doi.org/10.1093/ acprof:0so/9780199542673.001.0001.

PEIRCE, C. S. (1983). Escritos coligidos. (3 ed.). São Paulo: Abril Cultural.

Prange, K. (2014). (Hr.). Herbart und Dewey. Pädagogische Paradigmen im Vergleich. (pp. 7-18). Jena: Garamond Verlag (Edition Paidei).

Rousseau, J.-J. (2003). Oeuvres complètes. Tomo III: Discours sur l'origine et les fondements de l'inégalité. Paris: Gallimard, Bibliothèque de la Plêiade.

\section{Claudio Almir Dalbosco}

Doutor em Filosofia pela Universidade de Kassel, em Kassel, Alemanha; professor da Universidade de Passo Fundo (UPF) em Passo Fundo, RS, Brasil.

\section{Angelo Vitório Cenci}

Doutor em Filosofia pela Universidade Estadual de Campinas (Unicamp), em Campinas, SP, Brasil; professor da Universidade de Passo Fundo (UPF) em Passo Fundo, RS, Brasil.

\section{Miguel da Silva Rossetto}

Doutor em Educação pela Universidade de Passo Fundo (UPF), em Passo Fundo, RS, Brasil; professor da Universidade de Passo Fundo (UPF) em Passo Fundo, RS, Brasil. 


\section{Endereço para correspondência}

Claudio Almir Dalbosco/ Angelo Vitório Cenci/ Miguel

da Silva Rossetto

Universidade de Passo Fundo

BR 285

São José, 99052900

Passo Fundo, RS, Brasil 